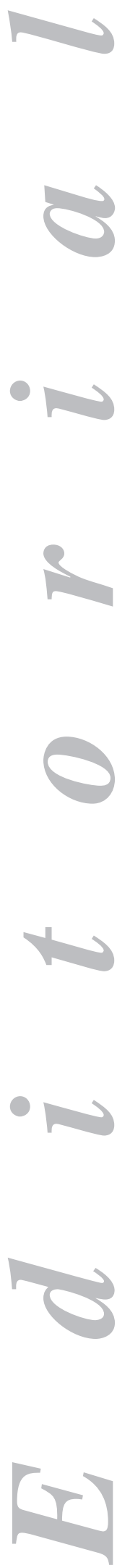

\title{
Cost-effectiveness of abdominal ultrasonography in the diagnosis of colorectal carcinoma
}

Colorectal cancer (CRC) is a most common neoplasm, and the second leading cause of cancer-related death. CRC was responsible for $11 \%$ of cancer-related deaths in males, and for $15 \%$ of cancer-related deaths in females according to data for year 2000. Most recent data reported in Spain on death causes in 2002 suggest that CRC was responsible for 12,183 deaths (6,896 males with a mean age of 70 years, and 5,287 women with a mean age of 71 years). In these tumors, mortality data do not reflect the true incidence of this disease, since survival has improved in recent years, particularly in younger individuals. In contrast to other European countries, Spain ranks in an intermediate position in terms of CRC-related incidence and mortality. This risk clearly increases with age, with a notorious rise in incidence from 50 years of age on. Survival following CRC detection and management greatly depends upon tumor stage at the time of diagnosis; hence the importance of early detection and -because of their malignant potential- of the recognition and excision of colorectal adenomas. Thus, polypectomy and then surveillance are the primary cornerstones in the prevention of CRC (1-4).

For primary prevention, fiber-rich diets, physical exercising, and the avoidance of overweight, smoking, and alcohol have been recommended. Low-dose NSAIDs or ASA are still not recommended for the prevention of CRC as of today (1).

CRC develops through well-established stages from lesions in colonic gland crypts to adenomas to cancer. The adenoma-carcinoma sequence is characterized by cumulative mutations in both suppressor genes and oncogenes, which affect the balance between cell proliferation and apoptosis; thus, each mutational event confers tumor cells with a growth advantage entailing a clonal expansion along multiple stages, and ultimately tumor progression (5).

From all the above, CRC screening is warranted: a) this tumor has a high incidence and results in severe morbidity and mortality; b) the premalignant potential of colorectal adenomas is well known; c) the tumor may be detected using highly sensitive endoscopic techniques; and d) early management improves survival. The population with a moderate risk for CRC includes individuals older than 50 years with no additional risk factors (family members with CRC or adenomas, chronic inflammatory bowel disease). Regarding the cost-effectiveness of CRC screening, Pignone et al. (6) performed a systematic review of this problem, and concluded that screening is cost-effective versus non-screening. The most cost-effective screening option for each population area or country remains to be established, as well as as its financial impact on healthcare systems (7-9). While no first-choice screening option has been established in our setting thus far, any one of those discussed below is more effective than non-screening. 
Studies reported with this regard suggest that fecal occult blood testing decreases CRC-related mortality. Alternatively, a meta-analysis by Scholefield (10) estimates that testing reduces mortality by $16 \%$. The technique's sensitivity is around $35 \%$, and specificity approaches $98 \%$. This technique has no adverse effects, and may therefore be easily accepted by the general population. Flexible sigmoidoscopy has a sensitivity of 70 to $80 \%$, but the detection of lesions in the portion amenable to this endocope requires a colonoscopy to the cecum. However, recent studies suggest that complete colonoscopy would not be mandatory for hyperplastic polyps (11). This technique is not riskless, but studies have shown that it helps reduce mortality from CRCs in the rectum-sigma. Complete colonoscopy is the "gold standard" for the detection of polyps and tumors within the colon. It additionally allows the excision of potentially malignant adenomas. Its complication rate, while low, is higher than that of the above-mentioned techniques. There is no evidence that CRC screening using an opaque enema contributes to a decrease in this tumor's incidence and mortality. Its sensitivity is lower than that of colonoscopy, it will neither detect small-size lesions, nor allow polyp excision. The usefulness of novel techniques for colonic examination -computerized tomography $(C T)$ colonography and magnetic resonance imaging (MRI) colonography- has also been assessed for CRC screening. Sensitivity and specificity approach 90 and $80 \%$, respectively. Also, it does not allow polyp excision or biopsy collection. Its sensitivity in the detection of flat polyps is lower than that of colonoscopy. Side effects include patient exposure to radiation during CT colonography, and rarely intestinal perforation (1,10,12-18). $\mathrm{Fe}$ cal DNA tests have been developed in recent years to detect tumor gene mutations in stools; their sensitivity and specificity vary according to test type and the population tested (asymptomatic or with symptoms suggesting a neoplasm); acceptance is good, but the cost of each individual test is high (19-21).

Abdominal ultrasonography is a cheap, convenient technique with no risk for complications. While it has been assessed in the detection of colon tumors, no data on its usefulness for CRC screening are available because of its low sensitivity in the detection of small-size lesions and polyps (22-30). The ability of abdominal ultrasounds to detect colonic lesions has been assessed in a number of studies; indeed, Schmutz (23) studied 453 abdominal echograms, evaluated their ability to detect colonic lesions (not just CRCs), and found a sensitivity of $77 \%$ and a specificity of 98\%; a study by Price and Metrewelli (22), which assessed a series of cases following the performance of 1,700 abdominal ultrasonograms, detected 35 possible CRCs and concluded that the positive predictive value of ultrasonography for CRC screening was $79 \%$, with a low rate of false positive results. Other studies have assessed ultrasonography in patients with suspected intestinal obstruction; thus, the study by Grunshaw et al. (27) assessed in 60 patients the ability of ultrasonography to diagnose intestinal (ileal or colonic) obstruction, which it did in $98 \%$ of patients while correctly diagnosing the cause of obstruction in $80 \%$; a study by Lim et al. (29) had the objective of assessing the ability of ultrasonography to establish both the site and cause of colonic obstruction; in 26 patients with colonic obstruction or suspected colonic obstruction it appropriately established the obstruction site in $85 \%$ of patients, and the cause of obstruction in $81 \%$. Studies focusing on CRC screening using ultrasonography offer similar sensitivities and specificities; the study by Rutgeerts et al. (28) in 95 patients obtained a sensitivity of $95.5 \%$, and a very low specificity; similar sensitivity estimates (96\%) were obtained by Richardson (25), but specificity was $67 \%$ and accuracy in lesion sitting was $91 \%$; Shirahama et al. (28) found that, among 41 echograms meeting ultrasonographic CRC di- 
agnostic criteria, the tumor was confirmed using opaque enema scans or colonoscopy in 37 patients (90\%). A study by Loftus et al. (30) compared the diagnostic utility of ultrasonography, CT, and colonoscopy for CRC recognition; these researchers found that the sensitivity and specificity of ultrasounds were very high (100\%), but diminished a lot when patients with polyps were included in the study group. As previously discussed, abdominal ultrasonography cannot detect colon polyps; the study by Limberg (26), comparing the usefulness of conventional abdominal ultrasounds versus hydrocolonic ultrasonography in 300 patients, reached a diagnosis of CRC in only 9 of 29 patients (sensitivity, 31\%) with conventional ultrasounds, whereas hydrocolonic ultrasonography correctly diagnosed $97 \%$ of cases; this same study suggests that conventional ultrasonography cannot detect polyps, whereas hydrocolonic ultrasonography can.

The study by Martínez-Ares et al., published in this issue of Revista Española de Enfermedades Digestivas (31), shows that the sensitivity of ultrasounds for CRC screening is $79 \%$, but increases to $91 \%$ when rectal ampullar lesions are excluded, with a specificity of $92 \%$. These rates are similar to those usually reported in the literature. The authors sustain that a selected group of patients may benefit from abdominal ultrasonography as a first diagnostic step. These would include patients with a low suspicion of CRC and no warning signs, or older, bedridden subjects with inappropriate colon preparation. Thus, for instance, in a study by our group (32) where we retrospectively evaluated colonoscopy indications, among 120 such requests where the only clinical sign was the presence of a "constitutional syndrome" (excluding patients with anemia or other warning symptoms) only 5 CRCs (4.2\%) and 19 colorectal adenomas (15.8\%) were detected. Chances to detect a $\mathrm{CRC}$ are very low in patients with only a constitutional syndrome for clinical manifestation, and no other warning symptoms or anemia.

In conclusion, abdominal ultrasonography in the diagnosis of CRC is a technique with acceptable sensitivity and specificity that lacks complications, is convenient for patients, may be rapidly performed, and requires no previous colon preparation; as a result, it may be useful in selected groups of patients, but further studies are needed to establish its value in the screening of the general population. The selection of a given screening method will depend on available resources, and their acceptance by the examined population. Presently, our recommendation would be fecal occult blood testing every one or two years and/or sigmoidoscopy every 5 years or colonoscopy every 10 years $(1)$.

M. Diago Madrid and J. M. Huguet

Service of Digestive Diseases. Consorcio Hospital General Universitario. Valencia, Spain

\section{References}

1. Grupo de trabajo de la guía de práctica clínica de prevención del cáncer colorectal. Guía de práctica clínica. Barcelona: Asociación Española de Gastroenterología, Sociedad Española de Medicina de Familia y Comunitaria y Centro Cochrane Iberoamericano; 2004. Programa de Elaboración de Guías de Práctica Clínica en Enfermedades Digestivas, desde la Atención Primaria a la Especializada: 4.

2. Ferlay J, Bray F, Pisani P, Parkin DM. GLOBOCAN 2000: cancer incidence, mortality and prevalence worldwide. $10^{\mathrm{a}}$ ed. Lyon: IARC Press, 2001.

3. Mortalidad por cáncer y otras causas en España, año 2000. Centro Nacional de Epidemiología, 2000. Disponible en: http://193.146.50.130/cancer/cancer1.htm. 
4. Winawer S, Fletcher R, Rex D, Bond J, Burt R, Ferruci J, et al. Colorectal cancer screening and surveillance: clinical guidelines and rationale-Update based on new evidence. Gastroenterology 2003; 124: 544-60.

5. Cruz-Bustillo. Molecular genetics of colorectal cancer. Rev Esp Enferm Dig 2004; 96: 24-59.

6. Pignone M, Saha S, Hoerger T, Mandelblatt J. Cost-effectiveness analyses of colorectal cancer screening: a systematic review for the U.S. Preventive Services Task Force. Ann Intern Med 2002; 137: 96-104.

7. Ladebaum V, Song K. Projected national impact of colorectal cancer screening on clinical an economic outcomes and health services demand. Gastroenterology 2005; 129: 1151-62.

8. O'Leary BA, Olynyk JK, Neville AM, Platell CF. Cost-effectiveness of colorectal cancer screening: comparison of community-based flexible sigmoidoscopy with fecal occult blood testing and colonoscopy. J Gastroenterol Hepatol 2004; 19 (1): 38-47.

9. Sonnenberg A. Cost-effectiveness in the prevention of colorectal cancer. Gastroenterol Clin North Am 2002; 31 (4): 1069-91.

10. Scholefield JH, Moss SM. Faecal occult blood screening for colorectal cancer. J Med Screen 2002; 9: 54-5.

11. Lin OS, Schembre DB, McCormick SE, Gluck M, Patterson DJ, Jiranek GC, et al. Risk of proximal colorectal neoplasia among asymptomatic patients with distal hyperplastic polyps. Am J Med 2005; 118 (10): 11139.

12. U.S Preventive Services Task Force. Screening for colorectal cancer: recommendations and rationale. Ann Intern Med 2002; 137: 129-31.

13. Imperiale TF, Wagner DR, Lin CY, Larkin GN, Rogge JD, Ransohoff DF.Risk of advanced proximal neoplasm in asymptomatic adults according to the distal colorectal findings. N Engl J Med 2000; 343: 169-74.

14. Ransohoff DF, Sandler RS. Screening for colorectal cancer. N Engl J Med 2002; 346: 40-4.

15. Muller AD, Sonnenberg A. Protection by endoscopy against death from colorectal cancer. A case-control study among veterans. Arch Intern Med 1995; 155: 1741-48.

16. Walsh JM, Terdiman JP. Colorectal cancer screening: clinical applications. JAMA 2003; 289: 1297-302

17. Pickhardt PJ, Choi JR, Hwang I, Butler JA, Puckett ML, Hildebrant HA, et al. Computed tomographic virtual colonoscopy to screen for colorectal neoplasia in asymptomatic adults. N Engl J Med 2003; 349: 2191-200.

18. Fenlon HM, Nunes DP, Schroy PC, Barish MA, Clarke PD, Ferruci JT. A comparison of virtual and conventional colonoscopy for the detection of colorectal polyps. N Engl J Med 1999; 341: 1496-503.

19. Ahlquist Da, Skoletsky JE, Boynton KA, et al. Colorectal cancer screening by detection of altered human DNA in stool: feasibility of a multitarget assay panel. Gastroenterology 2000; 119: 1219-27.

20. Tagore KS, Lawson MJ, Yucaitis JA, et al. Sensitivity and specificity of a stool DNA multitarget assay panel for the detection of advanced colorectal neoplasia. Clin Colorectal Cancer 2003; 3: 47-53.

21. Imperiale TF, Ransohoff DF, Itzkowitz SH, Turnbull BA, Ross ME, for the colorectal cancer study group. Fecal DNA versus fecal occult blood for colorectal-cancer screening in an average-risk population. $\mathrm{N}$ Engl $\mathrm{J}$ Med 2004; 351 (26): 2704-14.

22. Price J, Metreweli C. Ultrasonographic diagnosis of clinically non-palpable primary colonic neoplasm. Br J Radiol 1988; 61 (723): 190-5.

23. Schmutz G, Jeung MY, Beigelman C, Nguyen D. Abdominal echography in colonic diseases. J Radiol 1990; 71 (2): 85-92.

24. Rutgeerts LJ, Verbanck JJ, Crape AW, Buyse BM, Guillebert GL. Detection of colorectal cancer by routine ultrasound. J Belge Radiol 1991; 74 (1): 11-3.

25. Richardson NG, Heriot AG, Kumar D, Joseph AE. Abdominal ultrasonography in the diagnosis of colonic cancer. Br J Surg 1998; 85 (4): 530-3.

26. Limberg B. Diagnosis and staging of colonic tumors by conventional abdominal sonography as compared with hydrocolonic sonography. N Engl J Med 1992; 327 (2): 65-9.

27. Grunshaw ND, Renwick IG, Scarisbrick G, Nasmyth DG. Prospective evaluation of ultrasound in distal ileal and colonic obstruction. Clin Radiol 2000; 55 (5): 356-62.

28. Shirahama M, Koga T, Ishibashi H, Uchida S, Ohta Y. Sonographic features of colon carcinoma seen with high-frequency transabdominal ultrasound. J Clin Ultrasound 1995; 23 (6): 359-65.

29. Lim JH, Ko YT, Lee DH, Lee HW, Lim JW. Determining the site and causes of colonic obstruction with sonography. Am J Roentgenol 1994; 163(5): 1113-7.

30. Loftus WK, Metreweli C, Sung JJ, Yang WT, Leung VK, Set PA. Ultrasound, CT and colonoscopy of colonic cancer. Br J Radiol 1999; 72: 144-8.

31. Martínez-Ares D, Martín-Granizo Barrenechea I, Souto-Ruzo J, Yañez López J, Pallarés Peral A, VázquezIglesias JL. Rentabilidad de la ecografía abdominal en el diagnóstico del cáncer de colon. Rev Esp Enferm Dig 2005; 97 (12): 877-86.

32. Durá AB, Rodríguez E, Bort I, Huguet JM, Sempere J, Canelles P, et al. Síndrome constitucional o dolor abdominal, ¿justifican por sí solos la petición de colonoscopia? Gastroenterol Hepatol 2004; 27 (Supl. 5): 18. 